\title{
Perforated gastric ulcer with ST-segment elevation mimicking acute myocardial infarction
}

\author{
Wasawat Vutthikraivit MD
}

\begin{abstract}
A 78-year-old man presented to the emergency department with severe epigastric pain. An electrocardiogram showed ST-segment elevation in leads V2 and V3 consistent with acute myocardial ischemia. He denied any underlying disease. On physical examination, his abdomen had hypoactive bowel sounds, diffuse rebound tenderness, and muscle guarding. An upright abdominal $x$-ray showed pneumoperitoneum, and emergency laparotomy was done. We present a case of perforated gastric ulcer presenting with ST-segment elevation with documented normal coronary arteries. The ST-segment elevation reverted to normal after the surgery.
\end{abstract}

Keywords: ST-Segment elevation, acute abdomen, gastric perforation

\section{INTRODUCTION}

Electrocardiograms have an essential role in establishing the diagnosis of acute myocardial infarction in conjunction with the clinical presentation and cardiac markers. The ST-segment elevation on an electrocardiogram from an occlusive thrombus represents myocardial infarction. ${ }^{1}$ Although the electrocardiogram is an important tool in the diagnosis of acute myocardial infarction, it is vital to know that acute infarction is not the only cause of ST-segment elevation. ${ }^{1}$ Other causes include acute pericarditis, acute myocarditis, left ventricular hypertrophy, left bundle branch block, and other non-cardiac causes. ${ }^{1}$ We describe ST-segment elevation in patients without myocardial infarction as pseudo-myocardial infarction. ${ }^{2}$

Awareness of these pseudo-myocardial infarction cases is important for the clinician to avoid unnecessary thrombolytic treatment or percutaneous intervention and potentially dangerous complications.

Corresponding author: Wasawat Vutthikraivit Contact Information: wv.vutthikraivit@ttuhsc.edu DOI: $10.12746 /$ swrecc.v8i33.639
CASE

A 78-year-old man presented to the emergency department with sudden epigastric pain lasting 3 hours. $\mathrm{He}$ has no underlying disease. At the time of presentation his blood pressure was $110 / 70 \mathrm{~mm} \mathrm{Hg}$, his pulse rate was 80 beats per minute, and his body temperature was $37.0^{\circ} \mathrm{C}$. The 12-lead electrocardiography disclosed ST-segment elevation in leads V2 and V3 (Figure 1A), consistent with acute anterior myocardial infarction. Auscultation of the chest and heart showed normal breath sounds and the absence of cardiac murmurs, and there was no jugular venous distension or pitting edema of the legs. However, examination of abdomen disclosed hypoactive bowel sounds, generalized abdominal guarding, and rebound tenderness. Cardiac markers tests revealed a troponin $T$ less than $0.01 \mathrm{ng} / \mathrm{ml}$. The remaining tests, including complete blood count, electrolyte, blood urea nitrogen, and creatinine, were within normal limits.

A cardiologist was consulted, and transthoracic echocardiography revealed normal wall motion with an ejection fraction of $74 \%$. No vegetations or valvular disease were noted. An acute abdomen series was performed for suspect acute surgical condition. An 
A

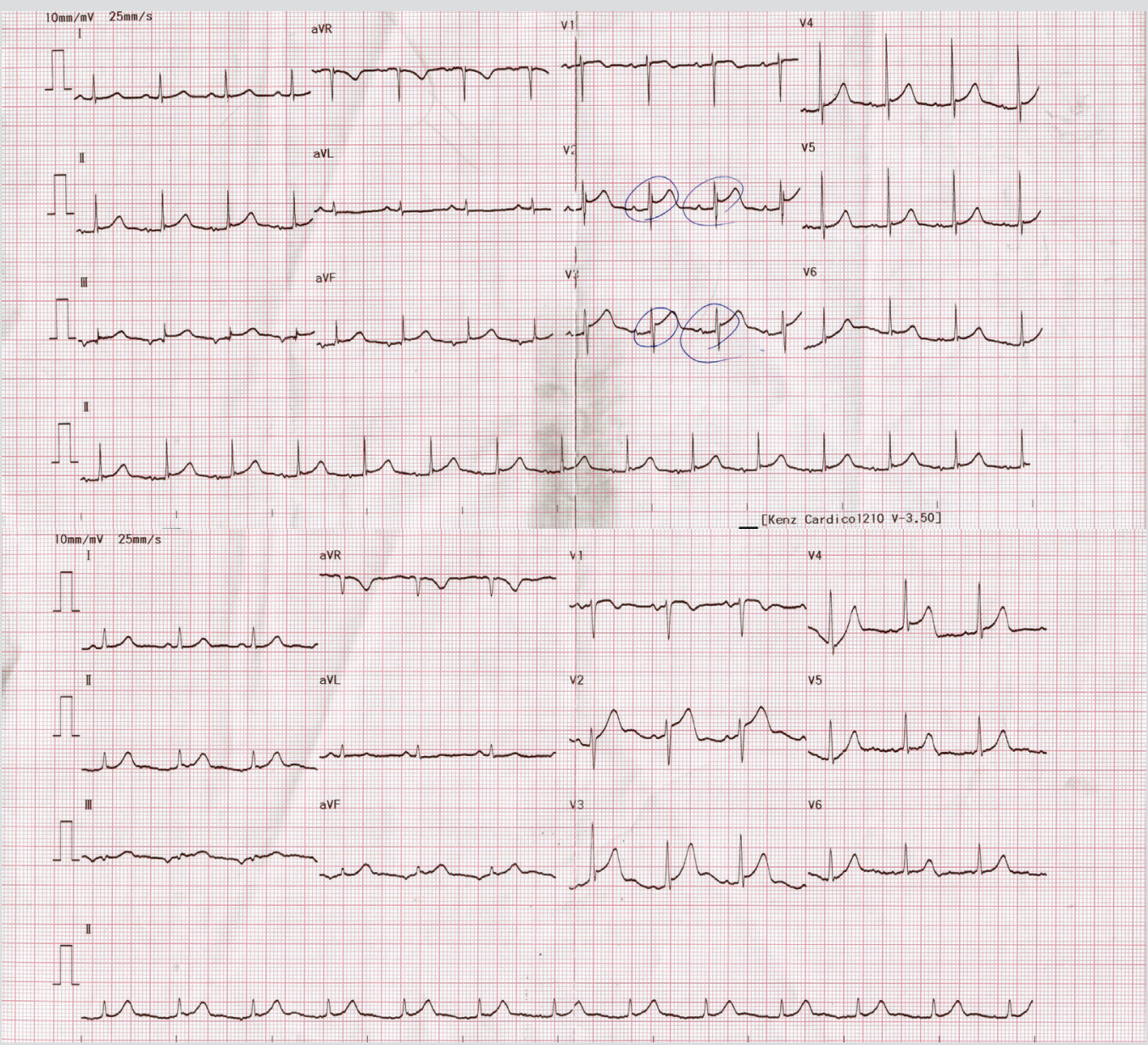

B

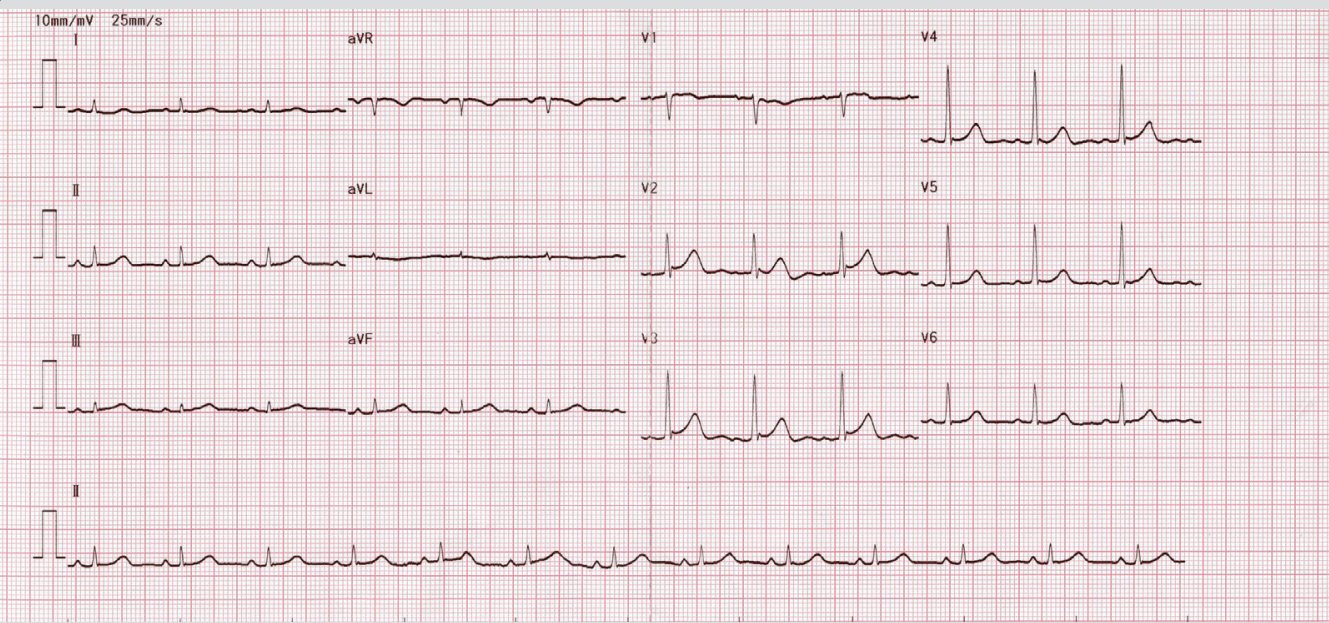

Figure 1. (A) ECG showed ST-segment elevation at the leads V2 and V3 at the time of initial presentation at the Emergency Room. (B) ECG showed the resolution of ST-segment elevation at the leads V2 and V3 after the operation. 


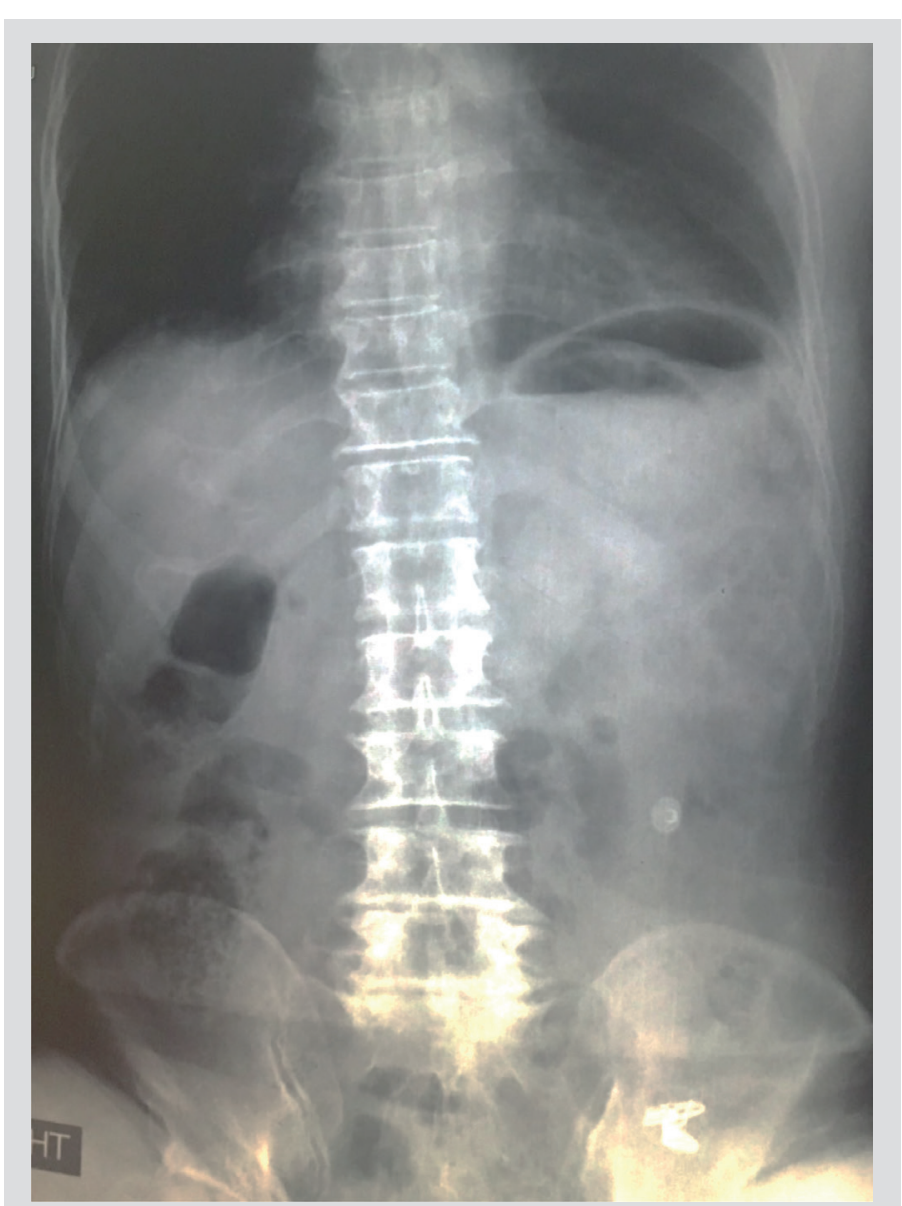

Figure 2. Upright abdominal x-ray showed free air under the Left diaphragm.

upright abdominal $\mathrm{x}$-ray showed free air under both diaphragms (Figure 2). He underwent emergency exploratory laparotomy, and a perforated gastric ulcer $1 \mathrm{~cm}$ in diameter was found. Simple suture and placement of abdominal drains were performed. A follow-up 12-lead electrocardiogram performed 24 hours after the operation revealed normalization of ST-segments in leads V2 and V3 (Figure 1B). Coronary computed tomography angiography (CTA) done after the patient was stabilized and revealed no significant stenosis of coronary arteries. Repeat cardiac markers remained normal. There were no complications during the postoperative course, and the patient was discharged seven days later.

\section{Discussion}

ST-segment elevation myocardial infarction (STEMI) usually results from an occlusive thrombus and is a leading cause of death. ${ }^{3}$ The earlier the diagnosis and treatment are performed, the more viable myocardium can be preserved as in the mantra "time is muscle." ${ }^{3}$ An electrocardiogram is a mainstay in the initial diagnosis of patients with clinical presentations that suggest acute myocardial infarction. ${ }^{1-4}$ Since electrocardiogram abnormalities can be found in many non-cardiac diseases, ${ }^{1}$ it is important to have more investigation, including cardiac markers and transthoracic echocardiography, to confirm the diagnosis in case the clinical features are not consistent with acute myocardial infarction. ${ }^{2}$ In emergencies, transthoracic echocardiography may help differentiate pseudomyocardial infarction and prompt a reevaluation for other etiologies. ${ }^{4}$ Moreover, complete physical examination and cardiac marker tests also have an important role in differentiation of pseudo-myocardial infarction as seen in our case.

We describe a 78-year-old patient who presented to the emergency department with sudden epigastric pain without a history of underlying diseases. The electrocardiogram revealed acute anterior wall myocardial infarction. Infarction of the anterior wall should cause shock and acute heart failure in patients. Without any sign of shock, jugular venous distension, and reciprocal ECG changes, our case was not consistent with acute myocardial infarction. Moreover, an abnormal abdominal examination, normal cardiac markers level, and normal transthoracic echocardiography prompted us to consider an acute abdomen. Exploratory laparotomy was done, and a perforated gastric ulcer was repaired that led to a normalization of ST-segments.

An acute abdomen is one of the other non-cardiac causes associated with pseudo-myocardial infarction but is rare. There are several reported cases of ST-segment elevation in patient with acute abdominal condition, such as acute cholecystitis, ${ }^{5-8}$ acute pancreatitis, ${ }^{9,10}$ acute appendicitis, ${ }^{11,12}$ and perforated duodenal ulcer. ${ }^{13,14}$ Several mechanisms have been 
postulated to explain the electrocardiogram changes associated with acute abdominal conditions, and these include prolonged hypotension leading to decreased coronary blood flow, vagal nerve stimulation, circulating proteolytic enzymes, increased myocardial oxygen consumption, and decreased oxygen delivery to the heart resulting from sepsis. ${ }^{11,12}$ Although many mechanisms have been postulated, the exact mechanism remains unclear. Since this patient had no history of shock and had a normal coronary CTA, the mechanism of transient ST-segment elevation in this case should be related to a perforated gastric ulcer rather than to acute coronary insufficiency.

In conclusion, perforated gastric ulcer should be recognized as a rare presentation causing ST-segment elevation. It is vital for clinicians to know that acute abdominal conditions are one of the causes of ECG change because a delay in diagnosis may lead to serious complications.

Article citation: Vutthikraivit W. Perforated gastric ulcer with ST-segment elevation mimicking acute myocardial infarction. The Southwest Respiratory and Critical Care Chronicles 2020;8(33):56-59

From: Department of Internal Medicine, Texas Tech University Health Sciences Center, Lubbock, Texas

Submitted: 12/9/2019

Accepted: $1 / 12 / 2020$

Reviewer: Scott Shurmur MD

Conflicts of interest: none

This work is licensed under a Creative Commons Attribution-ShareAlike 4.0 International License.

\section{REFERENCES}

1. Wang K, Asinger RW, Marriott HJ. ST-segment elevation in conditions other than acute myocardial infarction. New Engl J Med 2003;349(22):2128-35.

2. Nunes JP. Pseudo myocardial infarction-a condition in need to be redefined? Medical Hypotheses 2010;74(2):219-21.

3. Bates ER, Jacobs AK. Time to treatment in patients with STEMI. New Engl J Med 2013;369(10):889-92.

4. American College of Emergency P, Society for Cardiovascular A, Interventions, et al. 2013 ACCF/AHA guideline for the management of ST-elevation myocardial infarction: a report of the American College of Cardiology Foundation/American Heart Association Task Force on Practice Guidelines. J Amer Coll Card 2013;61(4):e78-140.

5. Ryan ET, Pak PH, DeSanctis RW. Myocardial infarction mimicked by acute cholecystitis. Ann Int Med 1992;116(3):218-20.

6. Krasna MJ, Flancbaum L. Electrocardiographic changes in cardiac patients with acute gallbladder disease. Amer Surg 1986;52(10):541-3.

7. Dickerman JL. Electrocardiographic changes in acute cholecystitis. J Amer Osteopathic Assoc 1989;89(5):630-35.

8. Faintuch J, Silva MM, Faintuch JJ, et al. [Electrocardiographic changes in acute cholecystitis]. Revista do Hospital das Clinicas 1982;37(1):17-20.

9. Khairy P, Marsolais P. Pancreatitis with electrocardiographic changes mimicking acute myocardial infarction. Canadian J Gastro 2001;15(8):522-6.

10. Fulton MC, Marriott HJ. Acute Pancreatitis Simulating Myocardial Infarction in the Electrocardiogram. Ann Int Med 1963;59:730-2.

11. Dewar C, Siddiqi A, Kayani J. Pseudomyocardial infarction associated with a retrocaecal gangrenous appendix. Emerg Med J 2002;19(5):481-2.

12. Liao WI, Tsai SH, Chu SJ, et al. Acute ruptured appendicitis and peritonitis with pseudomyocardial infarction. Amer J Emerg Med 2009;27(5):627:e5-8.

13. Isaac J, Tekant Y, Kiong $\mathrm{KC}$, et al. Laparoscopic repair of perforated duodenal ulcer. Gastro Endo 1994;40(1):68-9.

14. Sole DP, McCabe JL, Wolfson AB. ECG changes with perforated duodenal ulcer mimicking acute cardiac ischemia. Amer J Emerg Med 1996;14(4):410-1. 